\title{
Revisiting Interactive Art Systems
}

\author{
Sean Clark \\ School of Art and Design, De Montfort University \\ The Gateway, Leicester, LE1 9BH, United Kingdom \\ seanc@cuttlefish.com
}

\section{INTRODUCTION}

In their pioneering paper "The Creative Process Where the Artist is Amplified or Superseded by the Computer" (1973) Cornock and Edmonds describe a model for the classification of artworks according to their systemic behaviour. In this presentation I revisit this model, discuss its subsequent development (Edmonds, Turner \& Candy, 2004) and present an extension to it that incorporates my own research into the use of the theory of autopoiesis (Maturana \& Varela, 1987) as basis for an expanded description of the 'interactive art system'.

\section{ART SYSTEMS \& AUTOPOIESIS}

Cornock and Edmonds identified the 'art system' as consisting of the artist, the participant and participants, the artwork, the environment in which these elements are placed, and the dynamic processes or interactions that result. This is a classic system-oriented model and will be familiar to anyone who has studied systems theory in any discipline.

Maturana and Varela identify similar elements and relationships within their autopoietic model of biological systems and it was to this model I looked when considering how Cornock and Edmond's might be developed further.

The essence of Maturana and Varela's work is a description of how self-maintaining systems interact. Their work describes how such systems are able to maintain their structural organisation over time and co-evolve in response to each other and their environment. Despite being initially concerned with living systems, the concepts they introduce can be applied to systems generally and, I will argue, are particularly suited to describing interactive artworks.

By considering the relationship between the participant and the artwork in their terms I will demonstrate that it is possible to gain additional insight into the interactive process and the nature of interactivity. Similarly, by comparing the systemic properties of the artwork to those of an autopoietic system (such as the participant) I will show that the range of systemic properties that can be considered in the interactive art systems model can be expanded.

\section{ACTIVE MIRRORS \& MOVING PICTURES}

As an artist, the goal of my research into interactive art systems has been to support my creative practice. I will illustrate my presentation with a demonstration of current Active Mirror, Memory Place and Moving Pictures art systems.

The Active Mirror engages the participant, or participants, in a fast-moving feedback loop of interaction. Memory Place adds a memory to the system and rewards stillness rather than movement. Moving Pictures self-construct over time in response to changes in their environment.

All three art systems will be part of a major exhibition of new work by Sean Clark to be held in Leicester in August 2011. The evaluation of these artworks will form the next stage in the author's study in to the nature of interactive art systems.

\section{REFERENCES}

Cornock, S. and Edmonds, E. (1973) The Creative Process Where the Artist is Amplified or Superseded by the Computer, Leonardo, Vol. 6, 11-16. Pergamon Press.

Edmonds, E., Turner, G., Candy, L. (2004) Approaches to interactive Art Systems, Proceedings of the 2nd International Conference on Computer Graphics and Interactive Techniques in Australasia and South East Asia, June 15-18, 2004, Singapore.

Maturana, M. R. and F. J. Varela F. J. (1987) The Tree of Knowledge. Boston, MA. Shambhala Publications. 